\title{
SOSIALISASI APOTEKER CILIK SISWA SD NEGERI 110/IX KELAS 5 DAN 6 DI DESA KEMINGKING DALAM KABUPATEN MUARO JAMBI
}

\section{Armini Hadriyati, Nurhadisma, Ginanjar Satrio, Ulma Sintia, Amellia Pratiwi, Ayu Apriliya, Sesqia Rahma, Lara Syahila, Yoli Nopita Sari}

\author{
Program Studi Farmasi, Sekolah Tinggi Ilmu Kesehatan Harapan Ibu \\ arminimuas55@gmail.com, nurhadisma9@gmail.com
}

\begin{abstract}
The use of drugs, especially for children, needs special attention because not all children can take medication when sick. Also, in childhood, children need to get a lot of information about various professions to increase knowledge and provoke learning. Based on this, training of young pharmacists was conduct for elementary school students in Kemingking Dalam, which aims to introduce the pharmacist profession as a health worker and source of drug information and provide skills training and education on the use of appropriate drugs. This training was for elementary school students in grades 5 and 6 in Kemingking Dalam. The activities were carried out by 8 Pharmacy S1 students who were initiated with an explanation in class. Students learn to wash their hands, brush their teeth properly, play games to stick their hands to color, and then stamp them onto the board. And at the end of the event, they said that it is essential to wash their hands properly and brush their teeth properly so that they are not easily damaged.
\end{abstract}

Keywords: Young Pharmacists, Training, Elementary Students.

\begin{abstract}
Abstrak
Pemakaian obat kepada anak-anak harus mendapatkan perhatian khusus sebab tidak semua anak mampu meminum obat saat sedang sakit. Di samping itu di masa usia anak-anak memang seharusnya mendapatkan banyak informasi mengenai profesi-profesi agar dapat menambah pengetahuan dan memancing semangat menuntut ilmu. Maka oleh karena itu dilakukanlah pelatihan apoteker cilik kepada siswa Sekolah Dasar di desa kemingking dalam, yang mana tujuannya untuk mengenalkan profesi apoteker sebagai bagian dari tenaga kesehatan dan sumber informasi obat serta memberikan edukasi tentang penggunaan obat yang benar. Pelatihan ini di prioritaskan pada siswa SD kelas 5 dan 6 di desa kemingking dalam. Pelatihan tersebut dibimbing langsung oleh 8 mahasiswa S1 Farmasi yang diawali dengan penjelasan di dalam kelas. Kemudian dilanjutkan pelaksanaan kegiatan Colour Both yang dalam hal ini mengajarkan siswa bahwa betapa pentingnya mencuci tangan yang benar dan pentingnya menyikat gigi yang benar sambil mengajak anak-anak bermain game menempelkan tangan ke warna lalu di cap ke papan yang disediakan mahasiswa S1 Farmasi. Dan diakhir acara mereka menyampaikan bahwa betapa pentingnya mencuci tangan dengan sabun dengan benar serta menyikat gigi sesuai protokol kesehatan yang benar agar kelak gigi tidak mudah rusak.
\end{abstract}

Kata kunci: Apoteker Cilik, Pelatihan, Siswa SD. 


\section{PENDAHULUAN}

Sosialisasi adalah merupakan kegiatan tatap muka yang menyebabkan seseorang mengenal cara dalam berfikir, berperasaan, dan berperilaku sehingga membuat ia dapat berperan dalam kehidupan bermasyarakat.

Dalam bersosialisasi, seorang individu akan mengenal serta menyesuaian dengan keadaan tempat dia bersosialisasi. Melalui kegiatan sosialisasi, masing-masing masyarakat belajar mengenal serta mendalami tingkah laku apakah yang harus dilaksanakan, dan tingkah laku apakah yang tidak harus dilaksanakan.

Dari pemaparan tersebut, dapat kita pahami bahwa jika seseorang bersosialisasi pada dasarnya melakukan pengenalan terhadap norma-norma dan nilai di lingkungan sekitarnya. Sebuah proses yang memberikan nilai-nilai yang dibutuhkan untuk pembentukan sikap serta kepribadian. Saat melakukan sosialisasi, seseorang diharuskan mampu menyesuaikan diri dengan lingkungan sekitarnya. Mencakup aspek yang luas dalam hal ideide,perilaku, kebiasaan dan hubungan sosial (Anwar, 2018).

Apoteker merupakan bagian dari tenaga kesehatan yang mempunyai keahlian dibidang obat-obatan. Pada masa sekarang, masyarakat banyak belum tahu tentang apoteker. Dengan melalui sosialisasi apoteker cilik ini, kita berusaha untuk mengenalkan pekerjaan apoteker ini sebagai salah satu tenaga kesehatan yang mempunyai keahlian penggunaan obat bagi masyarakat yang biasa di jual di toko apotek.

Sangatlah perlu untuk memberikan pemahaman terhadap dunia kesehatan seperti apoteker ini sejak dini terhadap anak-anak. Jadi, apoteker cilik adalah suatu proses untuk meningktan peran apoteker secara lebih nyata sejak usia dini. (Devi Ristian Octavia, \& Muhtaromah Aisyah, 2019).

Di dusun Kemingking Dalam merupakan salah satu desa yang mempunyai lahan pertanian serta perkebunan yang luas. Sehingga ratarata penduduk disana banyak yang berprofesi sebagai petani. Ketika kami mencoba mensurvei keadaan penduduk disana sedikit yang tahu tentang profesi apoteker. Oleh karena itu kami sangat ingin memperkenalkan profesi apoteker ini kepada anak-anak sekolah dasar dusun kemingking dalam sehingga mereka tertarik menjadi seorang apoteker.

\section{METODE PELAKSANAAN}

Adapun kegiatan yang dilakukan di mulai dari persiapan materi sosialisasi apoteker cilik, lalu pengumpulan bahan yang akan di sosialisasikan yakni berupa; poster apoteker, perlengkapan sikat gigi dan permainan colour both sekaligus memperingati hari kanker anak sedunia. Metode yang kami laksanakan kepada siswa SD Negeri 110 desa Kemingking Dalam adalah berupa metode pendekatan serta pengenalan terhadap apoteker itu sendiri. Di dalam sosialisasi tersebut juga dijelaskan tata cara menyikat gigi serta mencuci tangan yang baik sesuai protokol kesehatan kepada siswa SD kelas 5 dan 6. 
HASIL DAN PEMBAHASAN

\section{Sosialisasi Apoteker Cilik kepada Siswa SD kelas 5 dan 6.}

Kegiatan sosialisasi apoteker cilik dilakukan pada hari senin, 17 Februari 2020 pada jam 8:00 WIB. Mahasiswa S1 Farmasi yang melakukan sosialisasi tersebut berjumlah 8 orang. Adapun jumlah kelas 5 dan 6 SD Negeri 110 desa Kemingking Dalam berjumlah 26 orang. Kegiatan ini dilaksanakan pertama bertatap muka terlebih dahulu kepada Kepala Sekolah SD Negeri 110 untuk meminta izin bersosialisasi. Kemudian bertatap muka dengan siswa SD kelas 5 dan 6.

Dalam sosialisasi tersebut disampaikan secara bertahap dimulai dari perkenalan nama dan pengenalan apoteker dan hal-hal yang berkaitan dengan itu. Siswa dan siswi tersebut terlihat bersemangat dengan materi yang disampaikan. Terlihat dari awal hingga akhir kegiatan siswa aktif dalam partisipasi dan bertanya serta menjawab pertanyaan yang diberikan oleh mahasiswa S1 Farmasi. Diawali dengan pengenalan apoteker dan pengenalan tentang penggunaan obat dan bentuk sediaan obat seperti tablet, kapsul, pulvis atau puyer, sirup kering, salep, obat tetes, kream dan lainnya. Yang kedua adalah penyampaian kepada siswa tata cara menyikat gigi yang baik dan benar. Adapun tata caranya yaitu;

1. Bersihkan dahulu permukaan dari gigi bagian atas dengan memutar sikat gigi ke bawah.

2. Bersihkan permukaan dari gigi bagian bawah dengan memutar sikat gigi ke atas.
3. Tahan dan putarkan sikat gigi dengan lembut pada bagian gusi.

4. Bersihkan permukaan gigi depan dengan menggosokkan dari dalam keluar.

5. Bersihkan permukaan gigi geraham dengan menggosokkan dari belakang ke depan kemudian dari dalam ke luar serta bagian luar ke dalam.

Yang ketiga, tata cara mencuci tangan yang baik dan benar yaitu;

1. Basahi seluruh tangan menggunakan air yang mengalir bersih

2. Gosokkan sabun pada telapak tangan serta sela-sela jari

3. Bersihkan kuku dengan menyeluruh.

4. Bilas tangan menggunakan air bersih

5. Keringkan tangan menggunakan handuk, atau keringkan dengan mesin pengering dan sejenisnya.

Setelah siswa siswi tersebut diberikan pengetahuan, lalu dilanjutkan dengan sesi tanya jawab kepada siswa tersebut dan diberikan hadiah berupa perlengkapan sikat gigi apabila mereka mampu menjawab pertanyaan yang diberikan.

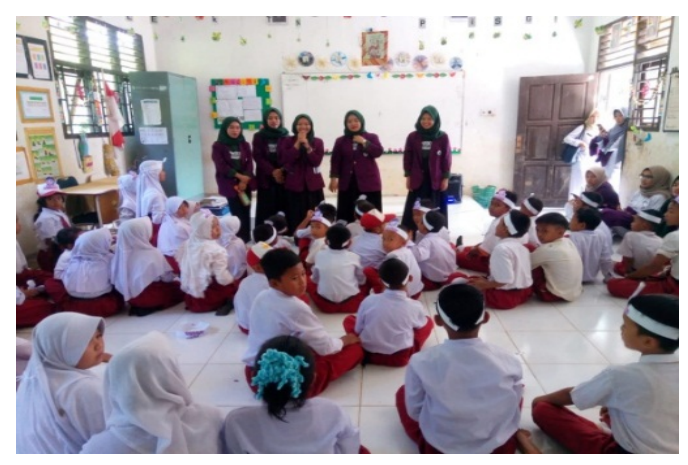

Gambar 1. Pengenalan Profesi Apoteker, Pemakaian Obat yang benar dan tata cara mencuci tangan 
serta menyikat gigi yang benar.

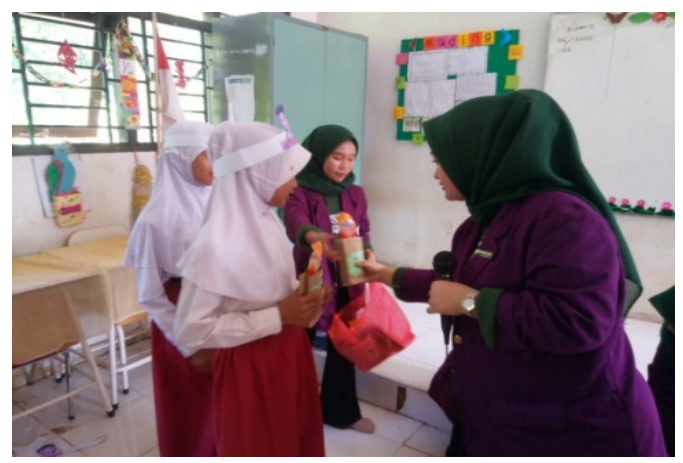

Gambar 2. Pemberian hadiah berupa perlengkapan sikat gigi.

Kegiatan yang ke empat adalah dalam memperingati hari kanker anak se dunia pada tanggal 15 Februari 2020. Dengan melaksanakan permainan yang di namakan Colour Both (mengecat tangan dengan warna yang di cap ke sepanduk yang telah disediakan Mahasiswa S1 Farmasi.

Berdasarkan hasil evaluasi kegiatan sosial yang telah dilakukan, dapatlah diambil kesimpulan bahwa siswa SD Negeri 110 Desa Kemingking Dalam menunjukkan tingkat pengetahuan tentang pekerjaan apoteker serta pemakaian obat yang tepat, terlihat dari hasil evaluasinya bahwa rata-rata siswanya ketika ditanya mampu menjawab dan menjelaskan apa itu apoteker, apa pekerjaannya dan seberapa besar peran seorang apoteker untuk masyarakat. Tidak hanya itu, siswa tersebut mampu memahami penggunaan obat yang baik, dan dapat mengenali macam-macam obat serta pemakaian obat yang benar.

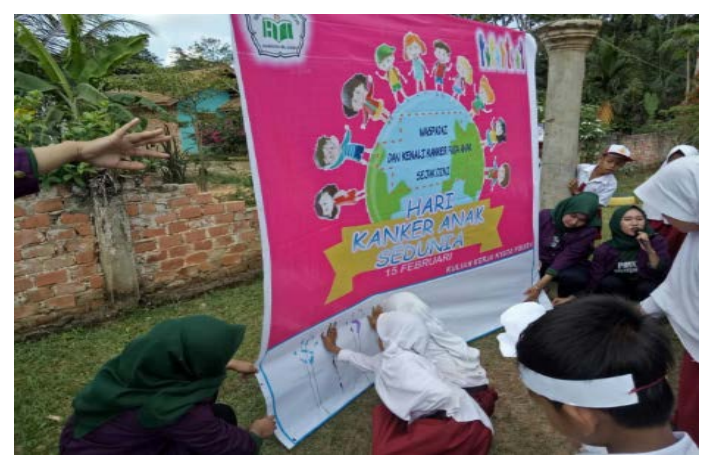

Gambar 3. Bermain Colour Both bersama siswa-siswi SD Negeri 110/IX

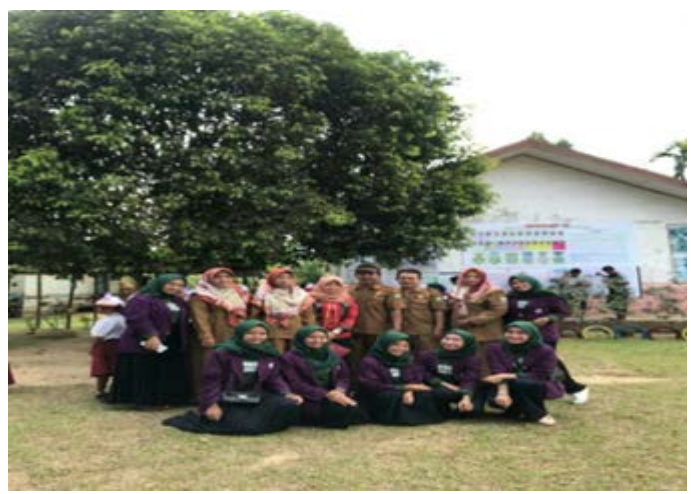

Gambar 4. Foto bersama Kepala Sekolah, Dosen Pembimbing Lapangan dan Jajaran Guru SD Negeri 110

\section{SIMPULAN}

Kegiatan yang dilaksanakan oleh Mahasiswa S1 Farmasi tentang sosialisasi apoteker cilik untuk siswa Sekolah Dasar Negeri 110/IX di Desa Kemingking Dalam Kecaman Taman Rajo Kabupaten Muaro Jambi berjalan dengan lancar. Perserta yang mengikuti kegiatan sosialisasi tersebut mendapatkan ilmu pengetahuan serta kemampuan akan hal ini, dan diantaranya ada yang tertarik ingin menjadi seorang apoteker suatu saat nanti. 
Armini Hadriyati, dkk. Sosialisasi Apoteker Cilik Siswa SD Negeri 110/IX Kelas 5 ...

\section{UCAPAN TERIMA KASIH}

Segenap Mahasiswa S1 Farmasi mengucapkan terima kasih kepada Dosen Pembimbing Lapangan dan masyarakat Kemingking Dalam terkhusus kepada Kepala Sekolah beserta jajaran guru di Sekolah Dasar Negeri 110/IX yang telah memberi izin serta dukungannya untuk kegiatan sosialisasi tersebut.

\section{DAFTAR PUSTAKA}

Anwar. 2018. Paradigma Sosialisasi dan Kontribusinya Terhadap Pengembangan Jiwa Beragama Anak. Jurnal AL- Maiyyah, Volume 11 No.1 Januari- Juni 2018

Devi, R. O dan Muhtaromah, A. 2019. Pelatihan Apoteker Cilik Siswa Sekolah Dasar Dalam Upaya Penggunaan Obat Yang Tepat Di Lamongan. Journal Of Character Education Society. Vol. 2, No.2, Juli 2019, Hal. 110. 